\title{
A PROFLLE OF SYDNEY WORLD MASTERS GAMES ATHLETES: HEALTH, INJURY AND PSYCHOLOGICAL INDICES
}

\author{
Joe Walsh, ${ }^{1, A, B, C, D}$ lan Timothy Heazlewood, ${ }^{1, A}$ Mark DeBeliso, , , A \\ Mike Climstein ${ }^{3,4,5, A, B, C, D}$ \\ ${ }_{1}^{1}$ School of Environmental and Life Sciences, Charles Darwin University, Darwin, Northern Territory, Australia \\ ${ }_{2}^{2}$ Physical Education and Human Performance Department, Southern Utah University, Cedar City, Utah, USA \\ ${ }^{3}$ School of Health and Human Sciences, Southern Cross University, Lismore, Australia \\ ${ }^{4}$ Exercise, Health and Performance Faculty Research Group, Faculty of Health Sciences, The University of Sydney, Sydney, New South Wales, \\ Australia \\ ${ }^{5}$ Water Based Research Unit, Bond University, Robina, Queensland, Australia

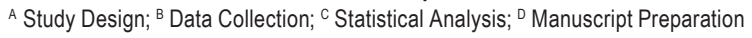

\author{
Address for corpespondence: \\ Joe Walsh \\ School of Environmental and Life Sciences, Charles Darwin University, \\ Darwin, Northern Territory, Australia \\ E-mail: jo.walsh@cdu.edu.au
}

\begin{abstract}
Ahstract The World Masters Games (WMG) are an international, multi-sport event which, in terms of competitor numbers, is the world's largest. The purpose of this manuscript was to summarize research to date that has been conducted on the WMG cohort. This paper also reports a descriptive and analytical overview of this large sample to document aspects of demographics and health indices for this population. Masters athletes demonstrated significant improvements in health related indices over age matched comparative national populations. Notable among these improvements were body mass index and cardiovascular disease (CVD) risk factors for the majority of participants, with female WMG participants presenting improved scores for CVD risk factors (blood pressure and high density lipoproteins, $p<0.05)$ and body mass index $(p<0.05)$ when compared to males. There were also improved lifestyle behaviors such as reduced smoking. A concern was improved health indices might be negated by increased injury from competitive sport at older ages, however findings did not support the premise of masters football code athletes having higher incidence of injury compared to younger athletes. With improved health indices associated with masters competition, it is relevant when promoting physical activity at older ages that the most motivating factor behind participation was socialization with others.
\end{abstract}

Key wordls Masters Sport, healthy aging, Quetelet index

\section{Introduction}

As defined by Raeburn and Dascombe (2008), masters athletes are those systematically training for and competing in organized sporting events designed specifically for older adults. Governed by the International Masters Games Association, the World Masters Games (WMG) are a non-invitational, quadrennial, international, multi-sport 
event. In terms of competitor numbers, the WMG has developed into the world's largest international sports event. The Sydney World Masters Games (SWMG) attracted 28,089 competitors who represented 95 countries competing in 28 sports (Sydney WMG Committee, 2010). In fact, the largest ever attendance at a WMG event was in Sydney, making this the largest international sporting competition (in terms of participant numbers) in the modern era. Participation at the WMG is open to sports people of all abilities and most ages, the minimum age criterion ranges between 25 and 35 years depending upon the sport.

The benefits of participation in masters athletic competition had been previously investigated with Hawkins and others reporting positive adaptations in musculoskeletal health (Hawkins, Wiswell, Marcell, 2003; Feland, Hager, Merrill, 2005; Seals et al., 1984; Whiteson, Bartels, Kim, Alba, 2006), improved glycaemia (Rogers, Kind, Hagberg, Ehsani, Holloszy, 1990; Pratley, Hagberg, Rogus, Goldberg, 1995) and considerable health benefits associated with the long-term exercise participation (Franklin, Fern, Voytas, 2004; Rosenbloom, Bahns, 2005; Shephard, Kavanagh, Mertens, Qureshi, Clark, 1995). Although long-term participation in sport (and physical activity (Olejnik, Kubińska, Pańczuk, Kubińska, 2017)) is advocated by health professionals, the advanced age of participants is also commonly associated with an increased incidence of chronic diseases such as coronary artery disease (Chugh, Weiss, 2015; Shapero et al., 2016), hypertension (HTN), hypercholesterolemia, and diabetes (Whiteson, Bartels, Kim, Alba, 2006). Although the WMG have been in existence since 1985, surprisingly there was limited scientific literature available on this specific cohort. An international team of researchers was thus formed to investigate the nexus between aging, physical activity, indices of health and the global obesity epidemic by investigating those competing in masters sport. The team investigated over 8,000 masters athletes competing at the 2009 Sydney WMG. The Sydney WMG was the largest sporting event by participant numbers and a high number of competitors took part in the research survey. It is therefore even possible this is the largest research survey (in terms of competitor numbers) ever conducted at a competitive sporting event.

\section{Research Purpose}

The purpose of this manuscript was to summarize key research to date that has been conducted on the WMG cohort, not only a unique and interesting population with relevance to such health concerns as the global obesity epidemic, but also possibly the largest ever sample of competitors from a competitive sports tournament. This paper also provides a high level descriptive overview of the WMG cohort to document various aspects of demographics and health indices for this population.

\section{Methodology}

Approval for this study was granted by a university Research Ethics Committee in accordance with the ethical standards of the Helsinki Declaration of 1975 (revised in 2008). The 2009 Sydney World Masters Games Organising Committee approved the project, stipulating the survey must only be provided in an online format so there was minimal disruption to the WMG participants during the WMG. An online survey was created using Limesurveytm, an open-source, web based application to deliver the survey. Filters were used in the participant questionnaires to abbreviate response times. Following pilot testing by investigators, electronic invitations were sent to masters games athletes who provided a valid email address upon registration. The survey consisted of several sections. These sections featured questions related to the following areas: information for participants, a privacy statement, participant demographics, participant medical history (personal and family), past surgical procedures, prescribed 
medications, physiologic data and psychological participation factors. The Sydney WMG Survey Process is displayed in Figure 1.

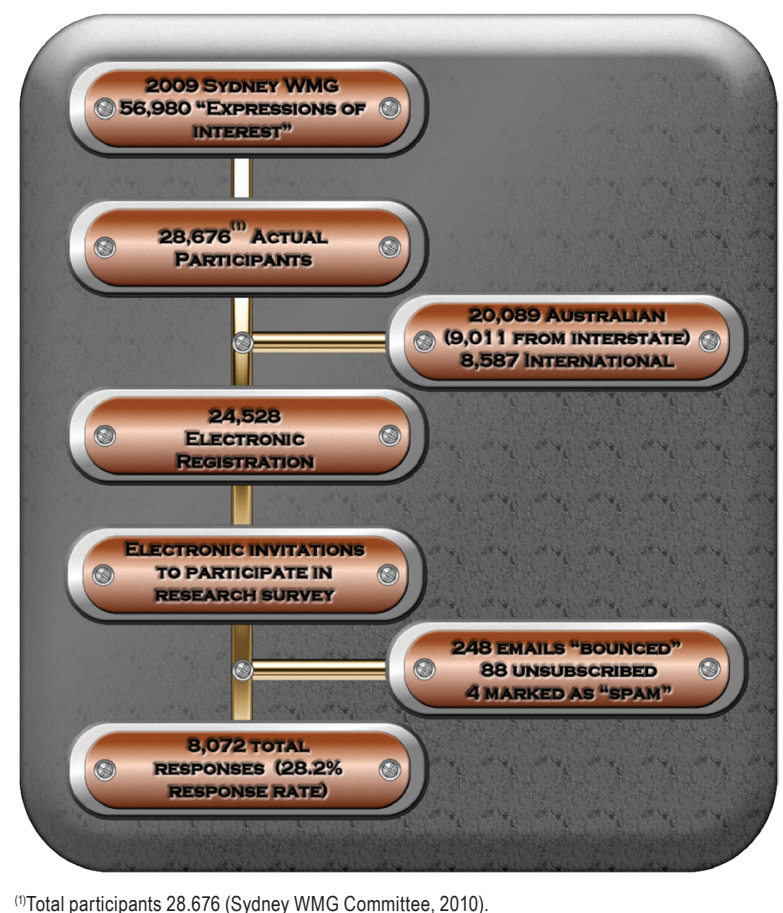

Figure 1. 2009 Sydney WMG Survey Process

\section{Summary statistics and analyses for the Sydney WMG masters athletes sample}

This section of the manuscript contains a high level descriptive overview, with some summary analyses for the masters athletes at the SWMG.

\section{Population Pypamids}

To get an overview of the study participants, population pyramids were generated to examine the distribution of athletes across the whole sample and also the top five sports (ranking by competitor numbers). The WMG sample population pyramid for the dataset (mean age (yrs) $51.6(+9.9$, range 25 to 91), split by gender (males mean age $53.7+10.0$ years, range 25 to 91 and females (mean age $49.9+9.1$ years, range 26 to 91 ) is shown in Figure 2 . The population was fairly evenly divided with $51.5 \%$ of the masters athletes male and $48.5 \%$ female. 


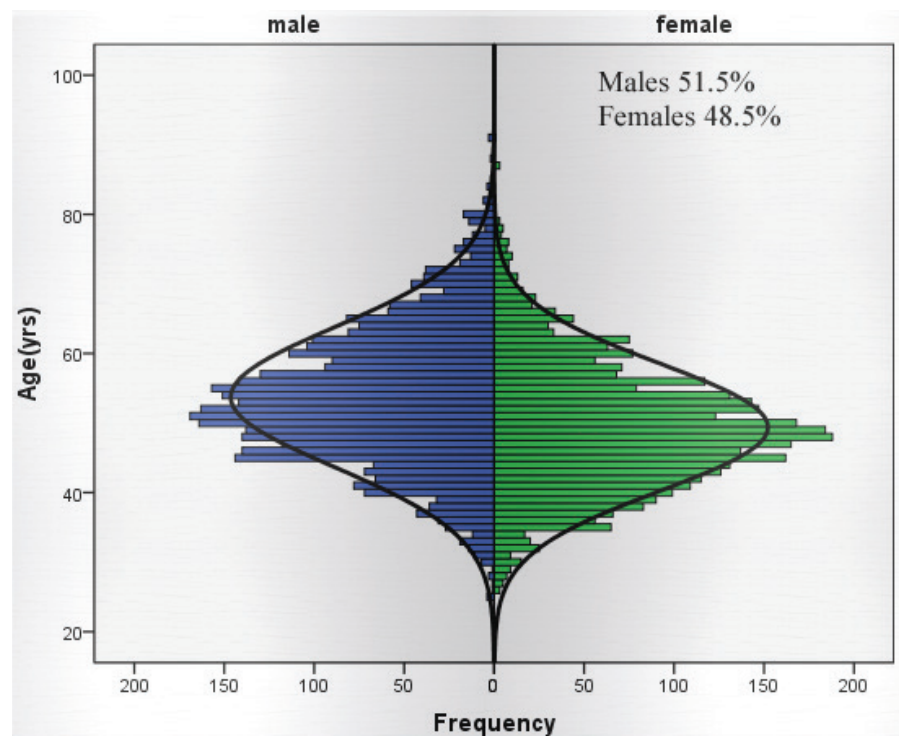

Figure 2. Population pyramid displaying participation demographics by gender. Line of normality displayed

The most represented nation in the survey was the games host nation, Australia. As demonstrated in Table 1, the five most represented countries in the survey provided the majority of participants $(94.9 \%)$.

Table 1. Distribution of participation by country for the five most represented countries

\begin{tabular}{clcc}
\hline Participation Rank & \multicolumn{1}{c}{ Country } & Participation by country & Percentage of total competitors \\
\hline 1 & Australia & 5,260 & 74.9 \\
2 & Canada & 695 & 9.9 \\
3 & New Zealand & 322 & 4.6 \\
4 & USA & 233 & 3.3 \\
5 & UK/Great Britain & 151 & 2.2 \\
\hline
\end{tabular}

A total of 28 different sports were played at the games with a number of the sports having multiple subcategories. Population pyramids by gender for the top five sports most represented in the survey are shown in figures $3-7$. Figure 8 shows the population pyramid by gender for the remaining sports at the games. 


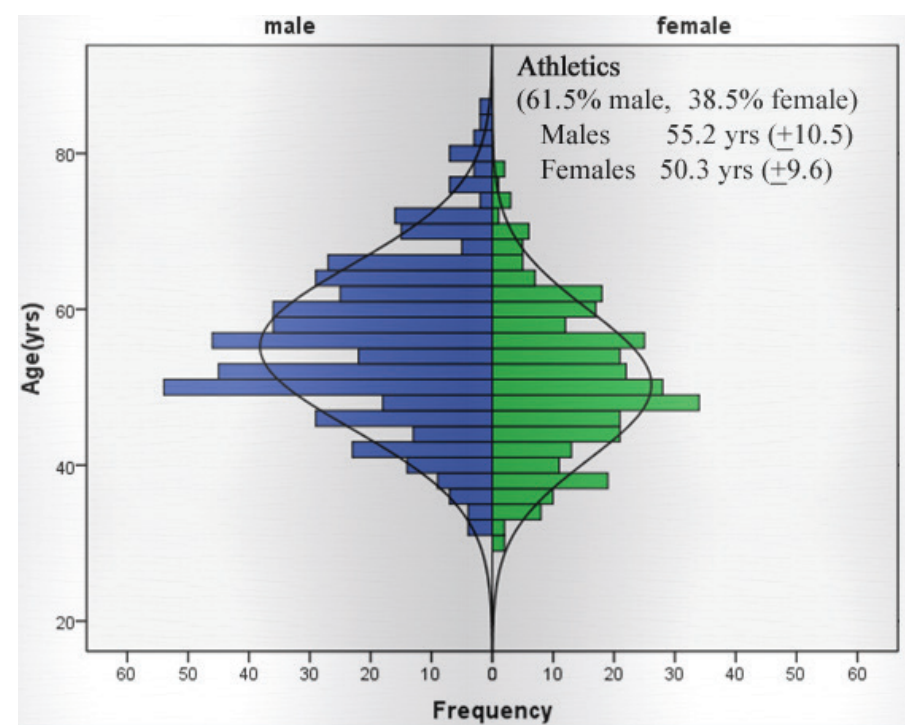

Figure 3. Athletics, $10.2 \%$ of participants

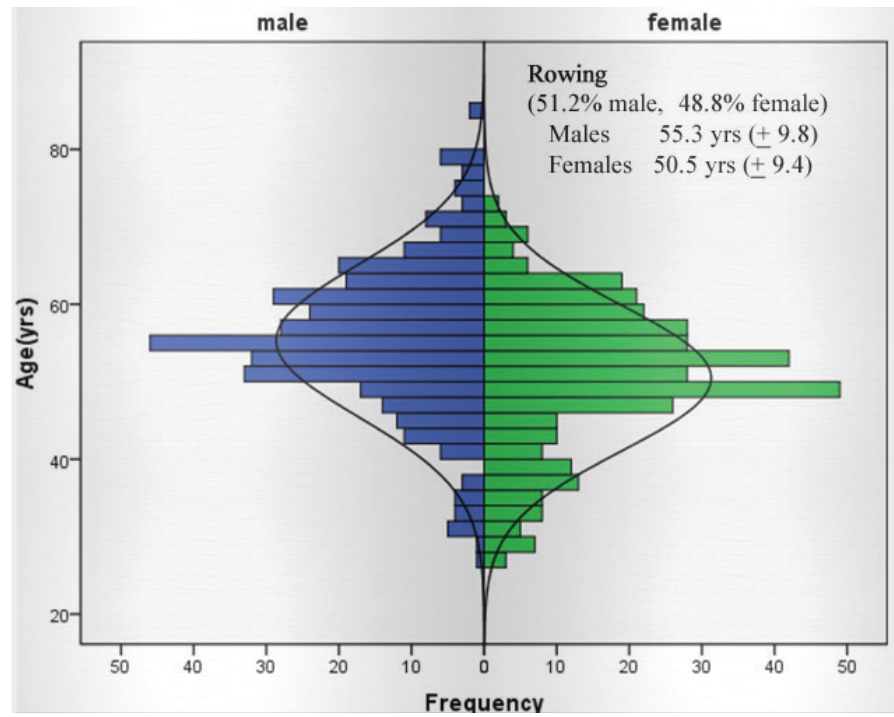

Figure 4. Rowing, $9 \%$ of participants 


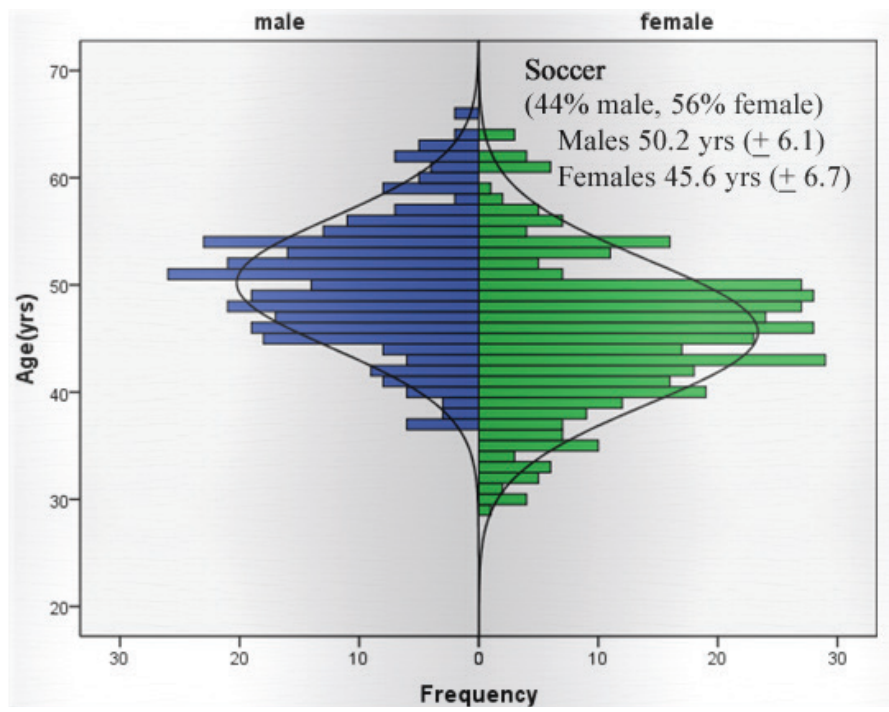

Figure 5. Soccer, $9 \%$ of participants

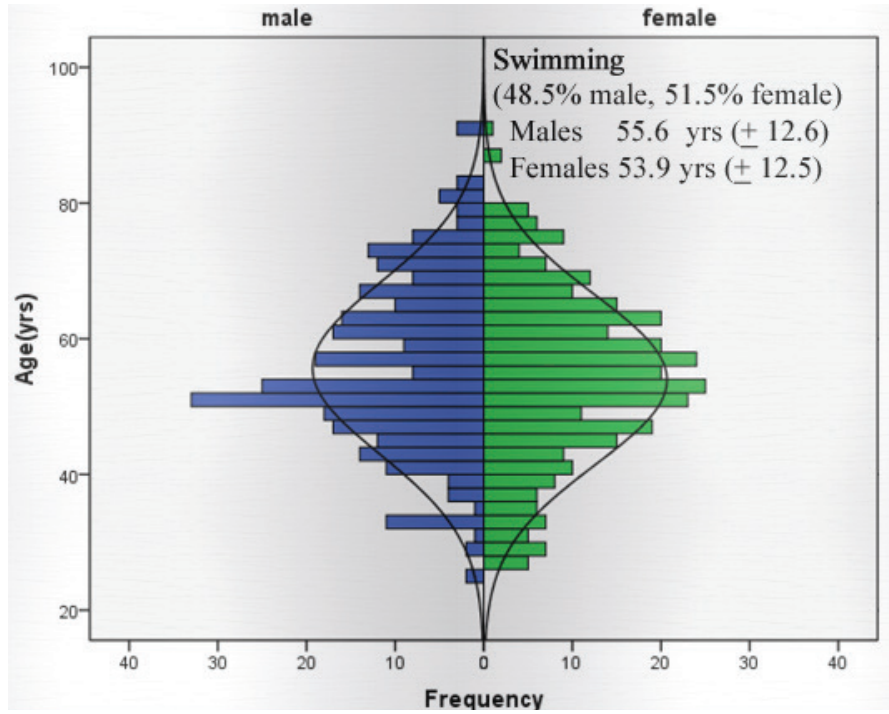

Figure 6. Swimming, $9 \%$ of participants 


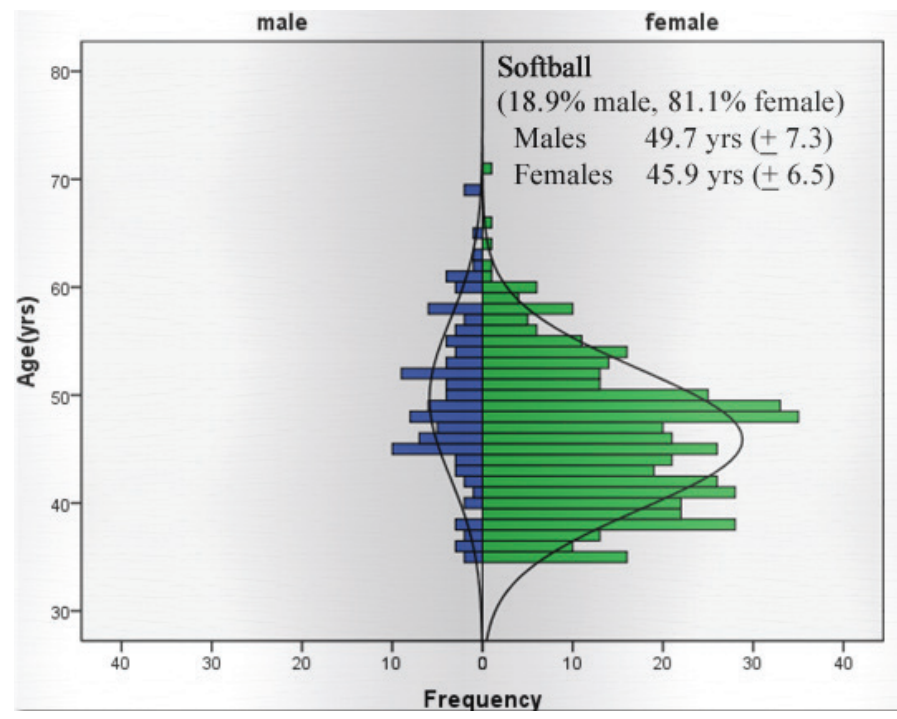

Figure 7. Softball, $9 \%$ of participants

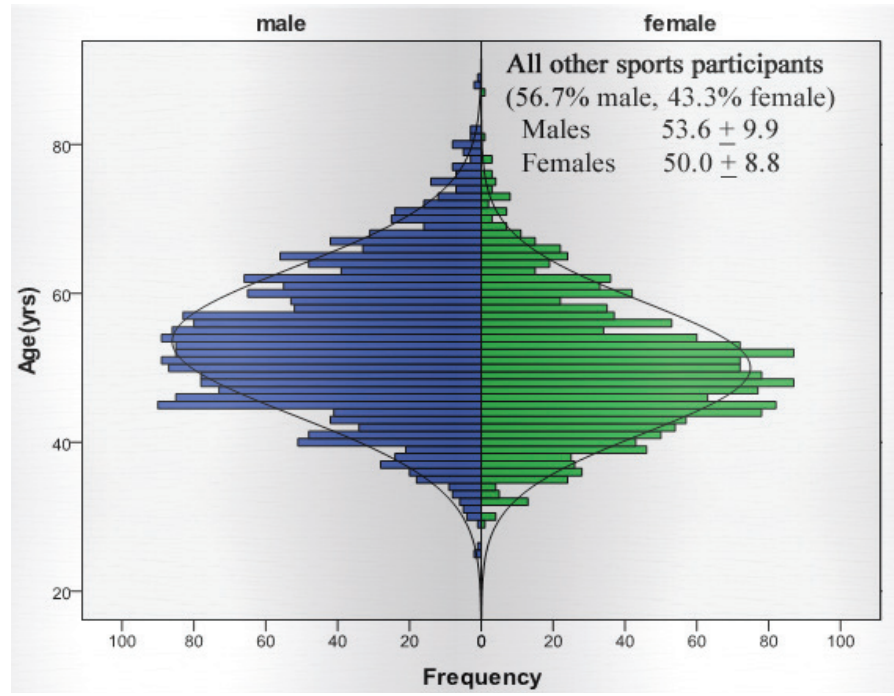

Figule 8: All "other" sports participants 
Given the majority of competitors were from Australia (Table 1) and running, swimming and soccer were among the most popular sports in Australia (Australian Bureau of Statistics, 2010), it is unsurprising that the most popular sports included soccer, swimming and athletics (which encompasses a number of distinct field disciplines as well as track/running disciplines).

\section{Chronic Disease, health and injury summary statistics}

Summary statistics for key chronic disease and important health summary statistical data are reported in this section for the WMG athletes. The incidence of chronic disorder, surgical procedure, use of prescribed (Rx'd) medications (HTN, hypolipidemic, nonsteroidal anti-inflammatory drugs (NSAID), bronchodilators), as well as the type and nature of injuries sustained during preparation for the games are represented in Table 2. The impact of injuries was also examined. For those participants that sustained injuries in preparation for the SWMG, those injuries resulted in an average of 47.4 days off training (range 1 to 1,100) and an average of 17.6 days off work (range 1 to 400$)$.

Table 2. Incidence of chronic disorder, surgical procedure, Rx'd medication, injury (type and locale)

\begin{tabular}{|c|c|c|c|c|c|}
\hline & & & & & \\
\hline & & $\begin{array}{l}\text { Population Incidence } \\
(\%)\end{array}$ & $\begin{array}{c}\text { Male } \\
(\%)\end{array}$ & $\begin{array}{c}\text { Female } \\
(\%)\end{array}$ & $\begin{array}{c}\text { (Pearson) Chi-Square } \\
\text { Statistic }\end{array}$ \\
\hline \multirow{5}{*}{ Chronic Disorder } & HTN & 9.5 & 60.1 & 39.9 & $25.6^{* *}$ \\
\hline & Rheumatoid and Osteoarthritis & 8.9 & 46.9 & 53.1 & $6.9^{\star \star}$ \\
\hline & Asthma & 8.7 & 41.2 & 58.8 & $33.3^{* *}$ \\
\hline & Hyperlipidemia & 6.4 & 65.2 & 34.8 & $42.8^{* *}$ \\
\hline & Depression & 6.3 & 39.1 & 60.9 & $33.5^{\star \star}$ \\
\hline \multirow[t]{3}{*}{ Surgical Procedure } & Knee replacement/repair & 10.3 & 52.0 & 48.0 & 0.1 \\
\hline & Hernia repair & 5.8 & 80.6 & 19.4 & $169.0^{* *}$ \\
\hline & Shoulder repair & 2.3 & 65.6 & 34.4 & $14.8^{\star *}$ \\
\hline \multirow[t]{4}{*}{ Prescribed Medication } & HTN & 7.4 & 61.9 & 38.1 & $28.9^{* *}$ \\
\hline & Hypolipidemic & 4.9 & 68.1 & 31.9 & $49.7^{\star *}$ \\
\hline & NSAID's & 6.4 & 43.7 & 56.3 & $9.8^{* *}$ \\
\hline & Bronchodilators & 4.0 & 39.8 & 60.2 & $18.2^{\star *}$ \\
\hline \multirow[t]{4}{*}{ Injury (type of injury) } & Muscle/tendon & 9.4 & 61.6 & 38.4 & $34.5^{\star *}$ \\
\hline & Joint pain & 5.4 & 58.8 & 41.2 & $9.7^{* *}$ \\
\hline & Inflammation & 4.6 & 53.9 & 46.1 & 0.9 \\
\hline & Muscle pain & 4.6 & 58.3 & 41.7 & $7.1^{* *}$ \\
\hline \multirow[t]{5}{*}{ Injury (location) } & Legs & 6.7 & 66.7 & 33.3 & $54.2^{* *}$ \\
\hline & Knee & 4.9 & 53.2 & 46.8 & 0.5 \\
\hline & Shoulder & 3.1 & 56.5 & 43.5 & 2.5 \\
\hline & Spine/back & 3.0 & 61.3 & 38.7 & $9.6^{* *}$ \\
\hline & Ankle & 2.7 & 58.6 & 41.4 & $4.5^{*}$ \\
\hline
\end{tabular}

${ }^{*}=p<0.05$ and $^{* *}=p<0.01$, indicate significant differences between genders.

Data on lifestyle behaviours such as smoking and drinking was also gathered for the masters athletes. A total of $3.6 \%$ of the survey participants were smokers, whilst $17.7 \%$ were ex-smokers. Amongst the smokers, the average number of cigarettes per week was 79 (range 1-279). This value is slightly lower $(-12.5 \%)$ than the 
average consumption of adults in Australia (88.9 cigarettes/wk) (Greenhalgh, Scollo, Bayly, 2017). A total of 73.5\% of the survey participants consumed alcohol, with an average consumption of 6.8 standard alcoholic drinks per week whilst $0.8 \%$ of participants identified themselves as ex-drinkers. This consumption is well below $(-116 \%)$ the Australian average of 14.7 standard drinks per week (Australian Bureau of Statistics, 2017).

\section{Summary of published findings to date}

In addition to the summary statistics and analyses on the SWMG athletes, further research has involved more granular analysis of this large cohort. Findings to date have furthered the understanding of the complex nexus between aging, physical activity, sports injuries, psychological factors associated with sports competition, health and obesity. Findings published in the literature are summarized in following sections.

\section{Body mass index and obesity}

WMG athletes demonstrated significant improvements in various health related indices compared to control groups (including an age matched comparative national population obtained via a data sharing agreement with the Australian Government Australian Bureau of Statistics). Notable among these improvements for masters athletes were body mass index for the majority, but not all participants. Research on SWMG swimmers (9\% obese vs. $21 \%$ obese as adult national average for Australia) (Walsh et al., 2013b), basketballers (13.2\% obese) (Walsh et al., 2013a), soccer players (9.1\% obese) (Walsh et al., 2012a) and other football code athletes $(11.8 \%$ obese overall, though $34.3 \%$ specifically for male rugby players) (Walsh et al., 2011a) overall demonstrated positive findings.

Due to the large number of participants, these sub-samples of athletes can be considered as representative samples of their sports at the SWMG. Results identified that body mass index (BMI) lay significantly more in the range considered as normal for masters athletes, as compared to a large general population of adult Australians. This finding indicated significantly improved health in terms of one health risk factor for WMG athletes compared to adult Australians. The significant improvement $(p<0.001)$ persisted across seven comparative national populations (for the U.K., summary statistics for three separate populations from each of England, Scotland and Wales were used). It was therefore appropriate to consider that the BMI of WMG athletes was lower than the general population from the constituent countries and that there was not significant causation by nationality for Australia.

Whilst comparison to several international populations was made, it was the Australian population that was of most relevance. The majority of athletes were from the Australian population (74.9\%), therefore this population was most applicable, however comparison to the other national populations was made in order to eliminate the possibility of some erroneous effect due to the WMG population being of mixed nationalities. As these other national populations were surveyed in a variety of ways (self-administered questionnaires, investigator administered questionnaires, physical measurements or combinations of these methods) care was taken when comparison was made to the self-administered questionnaire-based data on the WMG athletes. For this reason the Australian Bureau of Statistics (ABS) data using a self-reported heights and weights was appropriate to use, however the trend in difference $(p<0.001)$ persisted regardless of sampling procedures used in data collection.

Differences in BMI between the different sports at the Sydney WMG games was also investigated. Walsh et al. (2012d) compared BMI for 6,071 masters athletes across all 28 sports at the Sydney WMG. Differences in obesity prevalence were identified between sports (e.g. orienteering $2.51 \%$ obese vs. archery $39.13 \%$ obese). This may have indicated higher risk for conditions such as type 2 diabetes or heart disease in masters archery, 
shooting, rugby union, softball and baseball (Walsh et al., 2012d). However, it was indicated that there are other complex differences between the sports, including differences attributed to increased muscle mass, which would make it inappropriate to make recommendations of preferential participation solely on these findings for one index associated with health (Walsh et al., 2012d). Coaches of those sports demonstrating increased obesity prevalence were recommended to consider additional weight management strategies in their training regimes, particularly if there is no sporting benefit from increased BMI (Walsh et al., 2012d).

$\mathrm{BMI}$ is an important factor in the chronic disease burden within a population. Various studies have identified many characteristics and biochemical parameters as being significant factors behind obesity and elevated BMI (Das, 2011), requiring a multifaceted approach to alleviate the current obesity pandemic. Given the complexity of this problem and its connection to inactivity, these findings on this unique cohort of individuals were of special interest.

For a large representative sample of 6,071 athletes competing at the Sydney WMG, it was shown that for both male and female athletes, as well as for the sample as a whole, the more common trend of higher prevalence of higher BMI with increased age was reversed (Walsh et al., 2011b). Results of polynomial loess regression were closely matched to those of linear regression for the bulk of observational values (40-80 yrs) and showed further reduced $\mathrm{BMI}$ predictive values outside this range, though these areas were not as reliable for predictive purposes due to the lower density of observational readings in these areas (Walsh et al., 2011b). Despite a visually altered array of observational readings across the two genders, consistent negative gradient linear regression lines, as well as consistent loess regression curves were very encouraging results and confirmed the pattern within the data as being more reliable and non-gender specific on a macroscopic level (Walsh et al., 2011b).

\section{Smoking}

Smoking is one of the biggest public health threats and a prominent risk to health globally. Smoking is the most significant lifestyle behaviour as a cause of preventable death. Most prominent of the negative effects of smoking and passive smooking are associated cancer risks. However there are a myriad of negative effects both in terms of health and also social and economic disadvantage. Comparison was made between masters athletes competing in football codes (rugby unon, soccer, touch football) at the world masters games and data from the Australian Bureau of Statistics on smoking prevalence (Walsh et al., 2012b). In context of the popularity of the various football codes in Australia it was interesting to consider the smoking status of Sydney WMG athletes. It was hypothesised that improved lifestyle behaviours would be demonstrated by masters athletes. Smoking prevalence was lower than global (World Health Organisation) and Australian (ABS) comparitive data. It was possible that improved lifestyle behaviours might have contributed to improved economic status and health, allowing competition at older ages (Walsh et al., 2012b).

\section{Cardiovascular disease risk}

Cardiovascular disease (CVD) risk in Sydney WMG athletes was investigated for significant differences between 1,435 Sydney WMG masters athletes (567 female and 868 male, aged 27-91 years) and the Australian adult population (Debeliso et al., 2017). CVD data was gathered, including data on waist circumference (WC), systolic blood pressure (SBP), diastolic blood pressure (DBP), high-density lipoprotein (HDL), low-density lipoprotein (LDL) and total cholesterol (TC). Key findings included significant differences between genders with females 
significantly lower in BMI $(-5.3 \%, p<0.001)$, WC $(-10.6 \%, p<0.01)$, resting SBP $(-5.8 \%, p<0.01)$, resting DBP $(-8.4 \%, p<0.01)$, significantly higher in HDLs $(+15.2 \%, p<0.001)$ and significantly lower in both the TC:HDL ratio $(-12.6 \%, p<0.001)$ and LDL:HDL ratio $(19.0 \%, p<0.001)$. Significant differences $(p<0.001)$ were also identified when comparing WMG lipid results to the Australian general population (Australian Bureau of Statistics data for adult Australians). WMG demonstrated clinically superior TC (4.47 $\pm 1.11 \mathrm{mmol} / \mathrm{L})$, HDLs $(1.75 \pm 0.79 \mathrm{mmol} / \mathrm{L})$, and LDLs (2.92 $\pm 0.96 \mathrm{mmol} / \mathrm{L}$ ) when compared to Australian general population parameters (TC: $5.07 \mathrm{mmol} / \mathrm{L}$, HDL: $1.34 \mathrm{mmol} / \mathrm{L}$, LDL: $3.13 \mathrm{mmol} / \mathrm{L}$ ). This provided increasing evidence of improved health in masters athletes. WMG participants demonstrated improved values in a number of CVD risk factors when compared to the general population with female WMG participants presenting improved scores for CVD risk factors when compared to males. Hence, within the parameters of DeBeliso et al. (2017) Sydney WMG masters athletes exhibited evidence of superior health when compared to the general population within Australia.

\section{North American masters athletes at the Sydney WMG}

Further investigation was conducted focusing on North American Sydney WMG masters athletes ( $n=928$, age $52.6 \pm 9.8 \mathrm{yrs}$ ) identifying as representing USA or Canada (DeBeliso et al., 2011; DeBeliso et al., 2014). Chronic disease and disorder indicators reported by participants were significantly lower versus the general US population. Very few (2.5\%) reported currently smoking with an average of 65 cigarettes per week, while $13.6 \%$ were ex-smokers. Alcohol consumption ( $82.0 \%$ of the participants) averaged 4.7 drinks week, while $0.6 \%$ were ex-drinkers. The top five chronic disorders were rheumatoid arthritis or osteoarthritis (10.0\%), hypertension (HTN 9.1\%), hyperlipidemia $(8.0 \%)$, asthma (6.5\%), and depression (5.3\%). Top three operative treatments were knee replacement or repair $(12.2 \%)$, hernia repair $(6.1 \%)$, and herniated disc surgery $(2.0 \%)$. Top four prescription medications were antiHTN $(6.9 \%)$, thyroid hormones (6.6\%), hypolipidaemic (6.0\%), and medications to increase bone strength (5.9\%). Prevalence was significantly lower versus the general US population for HTN, hyperlipidemia, arthritis, asthma, and depression (all p-values <0.01).

DeBeliso et al. (2014) investigated the BMI of North American Sydney WMG competitors with respect to national health guidelines and demographics. A total of 928 (46.7\% male, $53.3 \%$ female) participants from Canada and the United States (aged $52.6 \pm 9.8$ years) completed the survey. The top 5 sports in which participants competed were football $(25.6 \%)$, track/field (15.4\%), swimming (8.4\%), volleyball $(8.2 \%)$, and softball $(7.8 \%)$. Female and male BMI $\left(\mathrm{kg} / \mathrm{m}^{2}\right.$ ) across all sports were: $>30 \mathrm{~kg} / \mathrm{m}^{2}$ (obese: $13.9 \%$ ), 25.00-29.99 kg/m² (overweight: $34.1 \%$ ), 18.50-24.99 $\mathrm{kg} / \mathrm{m}^{2}$ (normal: $50.3 \%$ ). The prevalence of obesity was significantly lower $(\mathrm{p}<0.05)$ for North American WMG competitors when compared to Canadian and US populations.

\section{Injury patterns}

Despite potential benefits for masters athletes in terms of reduced incidence of chronic disorders and improved indices of general health, there was concern that due to age related changes, increased risk of injury would be associated with highly competitive sport for the aging athlete. For masters football athletes at the Sydney WMG, the injury incidence during preparation for the tournament has similarities to, but was in fact shown to be significantly less than for other competitive sporting populations (Walsh et al., 2013c). Some gender and sport based differences in injury location and classification type were identified between different football codes (rugby union, touch football (a high participation sport in Australasia, see Walsh, Heazlewood, Climstein, 2012e)), soccer) (Walsh et al., 2013c). 
There were also no significant age related changes in injury nature (classification type, location, incidence, time off work or training) (Walsh et al., 2013c). Therefore the premise of masters football code athletes having a higher incidence of injury as compared to younger athletes was not supported (Walsh et al., 2013c). Further research (Heazlewood et al., 2017) conducted on 7,175 Sydney WMG masters athletes, rank ordered the injury data to compare male and female masters athletes. The rank order of injury location was similar for males and females with the highest ranked injury location being knees or legs. The rank order of injury classification was also similar for males and females with the highest ranked type of injury being a muscle or tendon strain. Injury rates were relatively low for females ranging from concussion ( $0.1 \%$ of injuries) to muscle or tendon strain $(8.4 \%)$. For males the injury rates ranged from dental or puncture injuries (both $0.1 \%$ of injuries) to muscle or tendon strain (12.6\%). Climstein et al. (2012) investigated the injury incidence in three diverse, but well represented sports soccer, rowing and swimming at the Sydney WMG. Results demonstrated differences injury patterns between the three sports in terms of location and consequences of the injuries. The injury consequences were measured in terms of days of work and training lost due to the injuries. Climstein et al. (2012) concluded that the incidence of injury was not sufficient to warrant a suggestion to not participate due to injury risk. This finding, similar to Walsh et al., (2013c), was considered a positive result due to the evidence health benefits from exercise.

\section{Pyschological motivations for competition}

With evidence of improved health indices associated with masters competition, it was logical to investigate factors connected with motivation to compete in masters sport. A section of the Sydney WMG survey tool incorporated 56 questions from a psychometric tool the motivations of marathoners scales (MOMS) (Masters, Ogles, Jolton, 1993). This was selected as past WMGs participants had age ranges with significant overlap to the age ranges used to develop the MOMS survey instrument. Additionally the items identified in the MOMS had been demonstrated in other studies (Ogles, Masters, 2003; Havenar, Lochbaum, 2007) as important motivational constructs.

Socialization with other participants was the most important personal motivation for masters sport participation (Adams et al., 2011; Heazlewood et al., 2011). Health and fitness were less important motivators than socializing to these masters level participants, but still stronger than motivating factors associated with competition (Adams et al., 2011; Heazlewood et al., 2011). Particularly notable was that as body mass index increased, masters athletes were more likely to be motivated by socialisation as opposed to weight loss (Walsh et al., 2012c), a finding that could influence marketing initiatives to increase exercise participation at older ages for obese participants. Sevene et al. (2012) examined 1,824 Sydney WMG athletes to determine if their motivations to compete were primarily intrinsic or extrinsic. Masters athletes at the Sydney WMG were equally motivated by intrinsic (e.g. to improve self esteem) and extrinsic (e.g. to earn the respect of peers) factors (Sevene et al, 2012). Heazlewood et al. (2016a) compared male and female Sydney WMG masters athletes to evaluate similarities and differences in participant motivation. Genders displayed similarities with factors associated with goal achievement, health orientation and affiliation as most important. Discriminant analysis indicated affiliation and competition as most discriminating with females having higher affiliation scores, whereas males displayed higher competition scores (Heazlewood et al., 2016a). Heazlewood et al. (2016b) examined machine learning procedures for predicting gender from psychological data collected based on motivations to compete at the Sydney WMG. It was demonstrated that using MOMS data, gender for Sydney WMG athletes could be predicted with accuracy of 64.4\% (Heazlewood et al., 2016b) using 
a multiplayer perceptron neural network (Fausett, 1994). Walsh, heazlewood, Climstein (2018) slightly increased this accuracy using gradient boosted decision trees (Friedman, 2001; Friedman 2002). If significant lift in accuracy was obtained, perhaps this could be used to provide a better understanding of the relationship between motivation to compete in masters sport and gender.

\section{Discussion}

A record of demographical data, including several indices of health (smoking, drinking, incidence of chronic disease/disorder, surgical procedure, Rx'd medication, injury history) was successfully collected for a large representative sample of athletes who participated in the 2009 Sydney WMG. This data will help allow an understanding of significant factors affecting this unique cohort as well as potential health implications for long-term exercise adherence as recommended by health professionals.

More detailed analysis (as reported in the literature) demonstrated WMG athletes demonstrated significant improvements in various health related indices over other populations as control groups, including an age matched comparative national population obtained from the Australian Government Australian Bureau of Statistics. Notable among these improvements for masters athletes were body mass index for the majority, but not all participants. Females also had lower BMI than male masters athletes. This evidence of improved classification in one index of health (reduced BMI) for masters athletes (when compared to the general population) implied there are either improved levels of this index of health with aging due to adherence to sport or possibly the reduced BMI is advantageous and contributes to this cohort adhering (or being attracted) to masters sport at older ages.

Smoking prevalence was lower than global (World Health Organisation) and Australian (ABS) comparative data. It was possible that improved lifestyle behaviours might have contributed to improved economic status and health, allowing competition at older ages.

As well as gender based differences, significant differences were also identified when comparing WMG lipid results to the Australian general population (Australian Bureau of Statistics data for adult Australians). WMG athletes demonstrated clinically superior TC $(4.47 \pm 1.11 \mathrm{mmol} / \mathrm{L})$, HDLs $(1.75 \pm 0.79 \mathrm{mmol} / \mathrm{L})$, and LDLs (2.92 $\pm 0.96 \mathrm{mmol} / \mathrm{L}$ ) when compared to Australian general population parameters (TC: $5.07 \mathrm{mmol} / \mathrm{L}, \mathrm{HDL}: 1.34 \mathrm{mmol} / \mathrm{L}$, LDL: $3.13 \mathrm{mmol} / \mathrm{L}$ ). This gave increasing evidence of improved health in masters athletes. WMG participants demonstrated improved values in a number of CVD risk factors when compared to the general population with female WMG participants presenting improved scores for CVD risk factors when compared to males. Hence, Sydney WMG masters athletes exhibited evidence of superior health when compared to the general population within Australia.

Then trend of improved health indices was reiterated in the reduced prevalence of chronic disease and disorder indicators reported by the North American participants of the Sydney World Masters Games compared to the US population. This included obesity where, the prevalence of obesity was significantly lower in incidence for North American WMG competitors when compared to Canadian and US populations.

With evidence of improved health indices associated with masters competition, it was logical to investigate factors connected with motivation to compete in masters sport. Socialization with other participants was the most important personal motivation for masters sport participation. Health and fitness were less important motivators than socializing to these masters level participants, but still stronger than competition. Particularly notable was that as body mass index increased, masters athletes were more likely to be motivated by socialisation as opposed 
to weight loss. Males and females displayed similarities with factors associated with goal achievement, health orientation and affiliation as most important. Discriminant analysis indicated affiliation and competition as most discriminating with females having higher affiliation scores, whereas males displayed higher competition scores. This information could perhaps be adopted by those promoting sport and physical activity for people at older ages, in order to encourage participation.

There was concern that due to age related changes, increased risk of injury would be associated with highly competitive sport for the aging athlete. Results demonstrated the injury incidence during preparation for the tournament had similarities to, but was in fact shown to be significantly less than for other competitive sporting populations. Some gender and sport based differences in injury location and classification type were identified. It was concluded that the incidence and consequences of injury was not sufficient to warrant a suggestion to not participate due to injury risk. This finding was considered a positive result due to the evidence for health benefits from exercise.

It has been shown by the research on Sydney WMG athletes, that there is evidenced for improved health within this cohort. Additionally there is not an associated increased risk of injury with these aging athletes. Based on this the promotion of such sport events for older athletes is supported, in order to promote potential health benefits with an acceptable risk of injury. Given this conclusion, seeking an improved understanding of the motivations behind masters athletes is justified. It was found there were some differences in motivations between males and females and also socialisation was one of the biggest motivating factors. Socialisation was in fact a greater motivating factor for obese than for non-obese athletes.

\section{Conclusion}

Health care professionals encourage physical activity and more specifically exercise adherence as a countermeasure to many chronic diseases and as a mechanism for successful aging. A record of demographical data, including several indices of health (smoking, drinking, incidence of chronic disease/disorder, surgical procedure, Rx'd medication, injury history) was successfully collected for a large representative sample of athletes who participated in the SWMG. The data reported and analyzed during this study suggests that the exercise adherence associated with competitive masters sport may reduce the incidence of many common chronic diseases in masters athletes. The scientific community may draw from these results a deeper understanding of various health related parameters affecting masters athletes as well as others that have demonstrated long-term exercise adherence across the lifespan. This data will allow a detailed understanding of significant factors affecting this unique cohort as well as potential health implications for long-term exercise adherence as recommended by health professionals.

\section{Acknowledgements}

Assistance was provided by the SWMG Committee in addition to technology support from Evan Wills from the Australian Catholic University. The assistance of the ABS for allowing access to the Australian National Health Survey 2007-2008 results via a data sharing agreement, was appreciated. Special thanks to the more than eight thousand masters athletes who took the time to participate in this project and contribute to the research on this unique cohort of athletes. 


\section{References}

Adams, K.J., DeBeliso, M., Walsh, J., Burke, S., Heazlewood, I.T., Kettunen, J., Climstein, M. (2011). Motivations to participate in sport at the Sydney 2009 World Masters Games. Medicine \& Science in Sports \& Exercise, 43 (5), 940.

Australian Bureau of Statistics (2010). Sports and recreation: A statistical overview. Canberra, Australia: Australian Bureau of Statistics. Retrieved from: http://www.ausstats.abs.gov.au/Ausstats/subscriber.nsf/0/17495BA58E1576F1CA2577C3000F2B8F/\$Fi le/41560_oct\%202010.pdf.

Australian Bureau of Statistics (2017). Apparent Consumption of Alcohol, Australia, 2015-16. Canberra, Australia: Australian Bureau of Statistics. Retrieved from: http://www.abs.gov.au/ausstats/abs@.nsf/mf/4307.0.55.001.

Chugh, S.S., Weiss, J.B. (2015). Sudden cardiac death in the older athlete. Journal of the American College of Cardiology, 65 (5), 493-502.

Climstein, M., Walsh, J., Heazlewood, I., DeBeliso, M., Adams, K., Sevene, T., Kettunen, J. (2012). Rowing, Soccer and Swimming: Injury differences (location, type, consequence) in preparation for the World Masters Games. Journal of Science and Medicine in Sport, 15, 129.

Das, R.N. (2011). Modeling of biochemical parameters. Model Assisted Statistics and Applications, 6 (1), 1-10.

DeBeliso, M., Adams, K.J., Climstein, M., Walsh, J., Burke, S., Heazlewood, I.T., Kettunen, J. (2011). World Masters Games: North American Participant Medical and Health History Survey. Medicine \& Science in Sports \& Exercise, 43 (5), 545.

DeBeliso, M., Sevene, T.G., Walsh, J., Adams, K.J., Kettunen, J., Heazlewood, I.T., Climstein, M. (2014). Body mass index of North American participants at the World Masters Games. Journal of Sports Science, 2 (4), 189-194.

DeBeliso, M., Walsh, J., Heazlewood, T., Sevene, T., Adams, K.J., Climstein, M. (2017). Cardiovascular Risk Profiles Of World Masters Games Participants: 1023 Board\# 202 May 31 2. Medicine \& Science in Sports \& Exercise, 49 (5S), 277.

Fausett, L. (1994). Fundamentals of neural networks: architectures, algorithms, and applications (No. 006.3). Prentice-Hall.

Feland, J.B., Hager, R., Merrill, R.M. (2005). Sit to stand transfer: performance in rising power, transfer time and sway by age and sex in senior athletes. British journal of sports medicine, 39 (11), e39.

Franklin, B.A., Fern, A., Voytas, J. (2004). Training principles for elite senior athletes. Current Sports Medicine Reports, 3 (3), $173-179$.

Friedman, J.H. (2001). Greedy function approximation: a gradient boosting machine. Annals of Statistics, 1189-1232.

Friedman, J.H. (2002). Stochastic gradient boosting. Computational Statistics \& Data Analysis, 38 (4), 367-378.

Greenhalgh, E.M., Scollo, M.M., Bayly, M. (2017). Self-reported measures of tobacco consumption. In: M.M. Scollo, M.H. Winstanley (eds), Tobacco in Australia: Facts and issues. Melbourne: Cancer Council Victoria; 2017. Retrieved from: http://www. tobaccoinaustralia.org.au/chapter-2-consumption/2-3-self-reported-measures-of-tobacco-consumption.

Havenar, J., Lochbaum, M. (2007). Differences in participation motives of first-time marathon finishers and pre-race dropouts. Journal of Sport Behavior, 30 (3), 270.13.

Hawkins, S.A., Wiswell, R.A., Marcell, T.J. (2003). Exercise and the master athlete - a model of successful aging? The Journals of Gerontology Series A: Biological Sciences and Medical Sciences, 58 (11), M1009-M1011.

Heazlewood, I.T., Walsh, J., Climstein, M., Burke, S., Kettunen, J., Adams, K.J., DeBeliso, M. (2011). Sport psychological constructs related to participation in the 2009 world masters games. World Academy of Science, Engineering and Technology, 7, $2027-2032$.

Heazlewood, I., Walsh, J., Climstein, M., Adams, K., Sevene, T., DeBeliso, M., Kettunen, J. (2016a). Participant motivation: A comparison of male and female athletes competing at the 2009 World Masters Games. In: Applied Psychology: Proceedings of the 2015 Asian Congress of Applied Psychology (ACAP 2015) (pp. 291-297).

Heazlewood, I., Walsh, J., Climstein, M., Kettunen, J., Adams, K., DeBeliso, M. (2016b). A comparison of classification accuracy for gender using neural networks multilayer perceptron (MLP), radial basis function (RBF) procedures compared to discriminant function analysis and logistic regression based on nine sports psychological constructs to measure motivations to participate in masters sports competing at the 2009 world masters games. In: Proceedings of the 10th International Symposium on Computer Science in Sports (ISCSS) (pp. 93-101). Springer, Cham.

Heazlewood, I., Walsh, J., Climstein, M., Adams, K., Sevrene, T., DeBeliso, M. (2017). Injury location, type and incidence of male and female athletes competing at the world masters games. Journal of Science and Medicine in Sport, 20, e51-e52.

Masters, K.S., Ogles, B.M., Jolton, J.A. (1993). The development of an instrument to measure motivation for marathon running: The Motivations of Marathoners Scales (MOMS). Research Quarterly for Exercise and Sport, 64 (2), 134-143.

Ogles, B.M., Masters, K.S. (2003). A typology of marathon runners based on cluster analysis of motivations. Journal of Sport Behavior, $26(1), 69$.

Olejnik, A., Kubińska, Z., Pańczuk, A., Kubińska, J. (2017). Physical Activity as a Health Need. Central European Journal of Sport Sciences and Medicine, 19 (3), 105-111. 
Pratley, R.E., Hagberg, J.M., Rogus, E.M., Goldberg, A.P. (1995). Enhanced insulin sensitivity and lower waist-to-hip ratio in master athletes. American Journal of Physiology-Endocrinology and Metabolism, 268 (3), E484-E490.

Reaburn, P., Dascombe, B. (2008). Endurance performance in masters athletes. European Review of Aging and Physical Activity, 5 (1), 31.

Rogers, M.A., King, D.S., Hagberg, J.M., Ehsani, A.A., Holloszy, J.O. (1990). Effect of 10 days of physical inactivity on glucose tolerance in master athletes. Journal of Applied Physiology, 68 (5), 1833-1837.

Rosenbloom, C., Bahns, M. (2005). What can we learn about diet and physical activity from master athletes? Nutrition Today, 40 (6), 267-272.

Seals, D.R., Hagberg, J.M., Allen, W.K., Hurley, B.F., Dalsky, G.P., Ehsani, A.A., Holloszy, J.O. (1984). Glucose tolerance in young and older athletes and sedentary men. Journal of Applied Physiology, 56 (6), 1521-1525.

Sevene, T., Adams, K., Climstein, M., Walsh, J., Heazlewood, I., DeBeliso, M., Kettunen, J. (2012). Are masters athletes primarily motivated by intrinsic or extrinsic factors? Journal of Science and Medicine in Sport, 15, S357.

Shapero, K., Deluca, J., Contursi, M., Wasfy, M., Weiner, R.B., Lewis, G.D., Baggish, A.L. (2016). Cardiovascular risk and disease among masters endurance athletes: insights from the Boston MASTER (Masters Athletes Survey To Evaluate Risk) initiative. Sports Medicine - Open, 2 (1), 29.

Shephard, R.J., Kavanagh, T., Mertens, D.J., Qureshi, S., Clark, M. (1995). Personal health benefits of Masters athletics competition. British Journal of Sports Medicine, 29 (1), 35-40.

Sydney WMG Committee (2010). Sydney 2009 World Masters Games Final Report. Sydney WMG Committee, Sydney, Australia.

Walsh, J., Heazlewood, I.T., Climstein, M., Burke, S., Adams, K., DeBeliso, M., Kettunen, J. (2011a). Body mass index for Australian athletes participating in rugby union, soccer and touch football at the World Masters Games. Journal of the World Academy of Science, Engineering and Technology, 7 (77), 1119-1123.

Walsh, J., Climstein, M., Heazlewood, I.T., Burke, S., Kettunen, J., Adams, K., DeBeliso, M. (2011b). The loess regression relationship between age and BMI for both Sydney World Masters Games athletes and the Australian national population. International Journal of Biological and Medical Sciences, 1 (1), 33.

Walsh, J., Burke, S., Climstein, M., Kettunen, J., Heazlewood, I.T., DeBeliso, M., Adams, K. (2012a). Obesity prevalence for athletes participating in soccer at the World Masters Games. International SportMed Journal, 13 (2), 76-84.

Walsh, J., Climstein, M., Heazlewood, I., DeBeliso, M., Kettunen, J., Sevene, T., Adams, K. (2012b). Reduced prevalence of smoking in masters football codes (rugby union, soccer and touch football). Journal of Science and Medicine in Sport, 15, 134.

Walsh, J., Heazlewood, I.T., Climstein, M., DeBeliso, M., Adams, K.J., Burke, S., Kettunen, J. (2012c). The effect of body mass index on motivations for competition at the Sydney World Masters Games. In: Proc. Pre-Olympic Conference: International Convention on Science, Education and Medicine in Sport. 19-4 July, SECC, Glasgow, UK. FC45.3.

Walsh, J., Heazlewood, I.T., Climstein, M., DeBeliso, M., Adams, K.J., Burke, S., Kettunen, J. (2012d). The Obesity Prevalence in Masters Athletes, a Comparison of all World Masters Games Sports. In: Proc. Pre-Olympic Conference: International Convention on Science, Education and Medicine in Sport. 19-24 July, SECC, Glasgow, UK. FC90.4.

Walsh, J., Heazlewood, I., Climstein, M. (2012e). Modelling touch football (touch rugby) as a Markov process. Intl J of Sports Sci and Eng, 6, 203-212.

Walsh, J., Climstein, M., Heazlewood, I.T., DeBeliso, M., Adams, K.J., Burke, S., Kettunen, J. (2013a). Body mass index of masters basketball players. Medicina Sportiva, 7, 1700-1705.

Walsh, J., Climstein, M., Heazlewood, I.T., Kettunen, J., Burke, S., DeBeliso, M., Adams, K.J. (2013b). Body mass index for athletes participating in swimming at the World Masters Games. The Journal of Sports Medicine and Physical Fitness, 53 (2), 162-168.

Walsh, J., Climstein, M., Heazlewood, I.T., DeBeliso, M., Kettunen, J., Sevene, T.G., Adams, K.J. (2013c). Masters athletes: No evidence of increased incidence of injury in football code athletes. Advances in Physical Education, 3 (1), 36-42.

Walsh, J., Heazlewood, I.T., Climstein, M. (2018). Application of gradient boosted trees to gender prediction based on motivations of master athletes. Model Assisted Statistics and Applications. 13 (3), 235-252.

Whiteson, J.H., Bartels, M.N., Kim, H., Alba, A.S. (2006). Coronary artery disease in masters-level athletes. Archives of Physical Medicine and Rehabilitation, 87 (3), 79-81.

Cite this article aS: Walsh, J., Heazlewood, I.T., DeBeliso, M., Climstein, M. (2018). A Profile of Sydney World Masters Games Athletes: Health, Injury and Psychological Indices. Central European Journal of Sport Sciences and Medicine, 3 (23), $37-52$. DOI: 10.18276/cej.2018.3-04. 